\title{
RELATIONSHIP BETWEEN GAS HOLDUP AND VOLUMETRIC MASS TRANSFER COEFFICIENT IN A BUBBLE COLUMN WITH SINGLE HOLE ORIFICES
}

\author{
HIROYUKI KAWASAKI, TATSUMI YAMAMOTO AND HISAYA TANAKA \\ Department of Chemical and Biochemical Engineering, Toyama University, Toyama, 930
}

Key Words: $\quad$ Mass Transfer, Bubble Column, Gas Holdup, Mass Transfer Coefficient, Single-Hole Orifice, Uniform Bubble Flow

\section{Introduction}

Gas holdup $\phi$ and volumetric mass transfer coefficient $k_{L} a$ are very important parameters for mass transfer operations in a bubble column. In some investigations ${ }^{1,2)}, k_{L} a$ has been empirically or semi-theoretically correlated as a function of $\phi$.

With increasing $u_{G 0}$, the flow regime in a bubble column usually changes from a uniform bubble flow to a heterogenous bubble flow via a transition regime ${ }^{5}$. It is a well-known fact that $\phi$ is a geometric property of a bubble. $k_{L} a$, however, is the dynamic property for mass transfer through the gas-liquid interface, because $k_{L}$ is influenced by transformation, coalescence, division and other phenomena associated with bubbles even if $\phi$ or $a$ are constant. Hence, the relationship between $\phi$ and $k_{L} a$ is very useful for analyzing the phenomenon for mass transfer.

In this paper, we related $k_{L} a$ as a function of $\phi$ in a bubble column with a single hole orifices and discussed the results obtained. When using this type of distributor, there is always a zone with few bubbles above the column bottom.

\section{Experimental}

The inner diameter and height of the bubble column used were $0.157 \mathrm{~m}$ and $2.03 \mathrm{~m}$, respectively. Three gas distributors were used, all with different single hole orifices ( $d=0.002,0.003$ and $0.005 \mathrm{~m}$ in diameter). In this study, estimates of $\phi$ and $k_{L} a$ were carried out using an airwater system. The liquid used was tap water at $303 \mathrm{~K}$. Unaerated liquid heights $Z_{0}$ were $0.51,1.0$ and $1.15 \mathrm{~m}$, respectively.

To measure the static pressure in the bubble column, fifteen pressure taps with hole diameters of $1 \mathrm{~mm}$ were inserted into the column and were connected to glass manometer tubes. The aerated liquid height $Z$ was determined by using the method of Yoshitome ${ }^{7)}$ because the total volume of bubbles dispersed throughout the liquid was minimal. $\phi$ was calculated using the following equation.

$$
\phi=\left(Z-Z_{0}\right) / Z
$$

The dissolved oxygen concentration $C$ was measured

\footnotetext{
* Received February 21, 1994. Correspondence concerning this article should be addressed to $\mathrm{H}$. Kawasaki.
}

and monitored with the use of an oxygen probe (YSI model 5739) connected to an oxygen meter (YSI model 54A) and a recorder. The probe was fixed at distances of $0.2,0.5$ and $0.8 \mathrm{~m}$ from the bottom of the bubble column for measurement at three $Z_{0}$ values. $k_{L} a$ was determined by the following equation under completely mixed conditions ${ }^{3)}$.

$$
k_{L} a=(1-\phi) \ln \left\{\left(C^{*}-C\right) /\left(C^{*}-C_{0}\right)\right\} / t
$$

\section{Results and Discussion}

\subsection{Average gas holdup}

Figure 1 shows the effects of $u_{G 0}, d$ and $Z_{\infty}$ on $\phi$. Each $\phi$ value increases with increasing $u_{G 0}$, though there is little effect of $d$ on $\phi$. At the same $u_{G 0}, \phi$ increases with $Z_{0}$. This effect of $Z_{0}$ on $\phi$ is caused by heterogeneity of bubble dispersion due to the unusual zone existing immediately above the column bottom. The results of Akita et al. ${ }^{1)}$ are shown in the same figure for comparison.

Since $\phi$ for each $d$ is directly proportional to $u_{G O}$ at low $u_{G 0}$, the bubble rising velocities $u_{B}\left(=u_{G O} / \phi\right)$ show constant values slightly increasing with $d$. Hence, the bubble flow in this region is regarded as a uniform bubble flow regime. The bubble flow in the region at higher $u_{G O}$ in this study is thus considered as the transition regime.

\subsection{Average volumetric mass transfer coefficient}

Figure 2 shows the effects of $u_{G 0}, d$ and $Z_{0}$ on $k_{L} a$ measured under the same $\phi$ conditions. From this figure, it is found that $k_{L} a$ increases linearly with increasing $u_{G 0}$, though there is a slight effect of $d$ on $k_{L} a$. The values of $k_{L} a$ increase with $Z_{0}$, when compared at the same $u_{G 0}$.

In the uniform bubble flow region, $k_{L} a$ for each $d$ is directly proportional to $u_{G 0}$. This increase seems to be caused by increasing the number of bubbles dispersed in the aerated liquid when both $k_{L}$ and $d_{B}$ are constant. In the transition region, while $k_{L} a$ linearly increases with increasing $u_{G 0}, \phi$ does not, as mentioned above. This fact suggests that there is a difference in mass transfer and/or bubble characteristics between the two bubble flow regimes.

\subsection{Relationship of $\mathbf{k}_{\mathbf{L}} \mathbf{a}$ by $\phi$}

Figure 3 shows a plot of $k_{L} a$ against $\phi$ for data obtained in the bubble column. From this figure, the rela- 


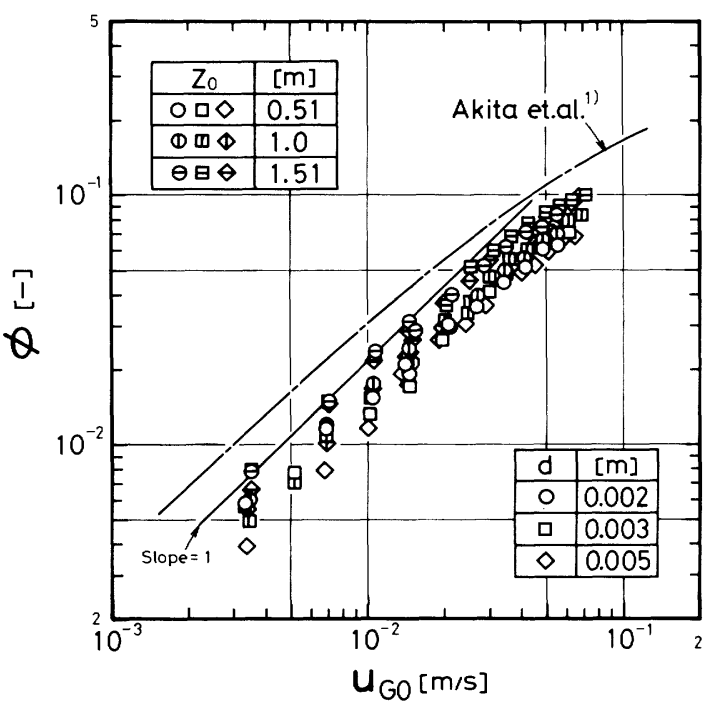

Fig. 1 Effects of $u_{G 0}, d$ and $Z_{0}$ on $\phi$

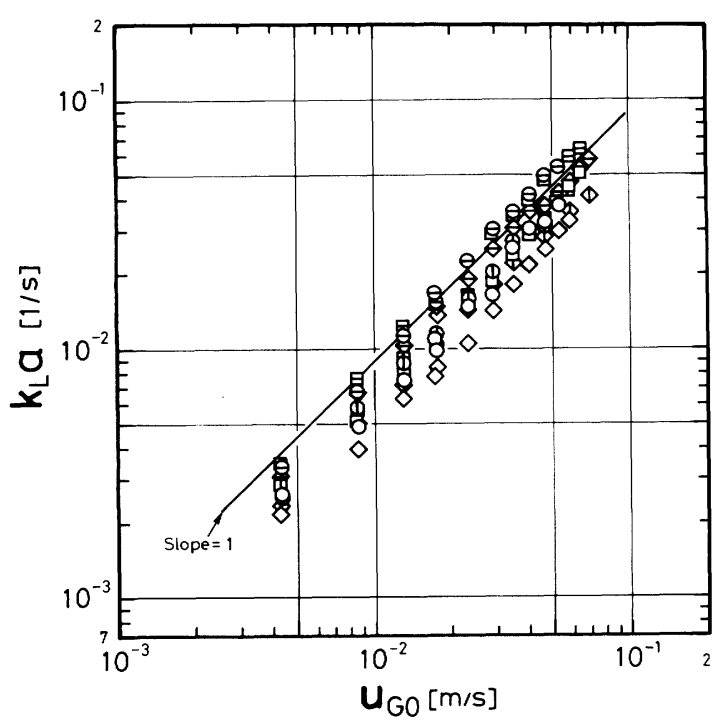

Fig. 2 Effects of $u_{G 0}, d$ and $Z_{0}$ on $k_{L} a$ (Keys as Fig. 1)

tionship for $k_{L} a$ is seen as two straight lines with slopes of 1.0 and 1.2 .

In the uniform bubble flow region, since both $k_{L} a$ and $\phi$ were directly proportional to $u_{G 0}$, the relationship for $k_{L} a$ showed unit slope. Assuming spherical bubbles with $d_{B}$, the relationship between $k_{L} a$ and $\phi$ is expressed by the following equation ${ }^{3)}$ ).

$$
k_{L} a=\left(6 k_{L} / d_{B}\right) \phi
$$

As shown in Fig. 3, since the relationship in this flow region can be represented by Eq. (3), $k_{L} / d_{B}$ is constant. Furtherfore, regarding $d_{B}$ as a constant value due to constant bubble rising velocity in this region, $k_{L}$ is constant also.

The relationship in the transition region had a

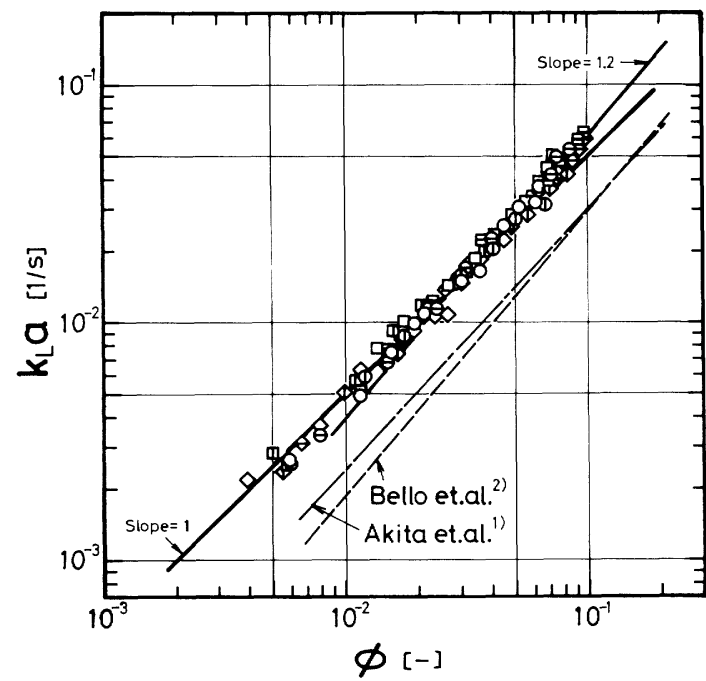

Fig. 3 Relationship between $k_{L} a$ and $\phi$ (keys as Fig. 1)

slightly larger slope with respect to $\phi$ than that in the uniform bubble flow region. Here, assuming that $k_{L} a$ is proportional to $\phi$ and that $d_{B}$ is constant due to extreme agitation of the gas-liquid mixed fluid ${ }^{4}, k_{L}$ slightly increases with $\phi$ and becomes larger than that in the uniform bubble flow region. This fact shows that the effects on $k_{L}$ of the behavior of the gas-liquid interface in each region are different. From this figure, it is clear that the change from the uniform bubble flow regime to the transition regime increases $k_{L} a$. The slope in this region agrees with the results of Bello et al. ${ }^{2)}$

\begin{tabular}{|c|c|c|c|}
\hline \multicolumn{4}{|c|}{ Nomenclature } \\
\hline$a$ & $=$ & gas-liquid interfacial area per unit aerated lic & aid \\
\hline$C$ & $=$ & concentration of oxygen in liquid & {$\left[\mathrm{kg} / \mathrm{m}^{3}\right]$} \\
\hline$C_{0}$ & $=$ & initial concentration of oxygen in liquid & {$\left[\mathrm{kg} / \mathrm{m}^{3}\right]$} \\
\hline$C^{*}$ & $=$ & saturation concentration of oxygen in liquid & {$\left[\mathrm{kg} / \mathrm{m}^{3}\right]$} \\
\hline$D$ & $=$ & tube diameter & {$[\mathrm{m}]$} \\
\hline$d$ & $=$ & hole diameter & {$[\mathrm{m}]$} \\
\hline$d_{B}$ & $=$ & mean bubble diameter & {$[\mathrm{m}]$} \\
\hline$k_{L} a$ & $=$ & volumetric mass transfer coefficient & {$[1 / \mathrm{s}]$} \\
\hline$t$ & $=$ & time & {$[\mathrm{s}]$} \\
\hline$u_{B}$ & $=$ & bubble rising velocity & {$[\mathrm{m} / \mathrm{s}]$} \\
\hline$u_{G 0}$ & $=$ & superficial gas velocity & {$[\mathrm{m} / \mathrm{s}]$} \\
\hline$Z$ & $=$ & aerated liquid heigth & {$[\mathrm{m}]$} \\
\hline$Z_{0}$ & $=$ & unaerated liquid heigth & {$[\mathrm{m}]$} \\
\hline$\phi$ & $=$ & average gas holdup & \\
\hline
\end{tabular}

Literature Cited

1) Akita, K. and F. Yoshida: Ind. Eng. Chem., Process Des. Dev., 12, 76-80 (1973)

2) Bello, R. A., C. W. Robinson and M. Moo-Young: Chem. Eng. Sci., 40, 53-58 (1985)

3) Chisti, M. Y. and M. Moo-Young: Biotechnol. Bioeng., 31, 487-494 (1988)

4) Koide, K.: "Hannou Kogaku", p. 125, Maki-Shoten (1988)

5) Maruyama, T., S. Yohida and T. Mizushina: J. Chem. Eng. Japan, 14, 352-357 (1981)

6) Yagi, H. and F. Yoshida: J. Ferment. Technol., 52, 905-916 (1974)

7) Yoshitome, H: Kagaku Kogaku, 27, 27-31 (1963) 